questionnaire (GERDQ) was given. The questionnaire consisted of demographic characteristics and the symptoms score for GERD. A symptoms score of at least 8 was considered as GERD. Data were analysed using descriptive statistics and chisquare test.

Results The median age of the subjects was 24.0 years old. Ecig smoking was frequent (74.2\%) among the subjects with median duration 2.0 years. The median of its dose was $30.0 \mathrm{ml}$ weekly. The prevalence of GERD in this study was 9.4\%. According to e-cig smoking status, the prevalence of GERD among smokers was $6.6 \%$, while the prevalence of GERD among nonsmokers was $17.4 \%$. The e-cig smoking was negatively associated with GERD ( $\mathrm{PR}=0.334$; 95\% CI: $0.144-$ $0.772 ; \mathrm{p}=0.008$ ) (table 1$)$.

\begin{tabular}{|c|c|c|c|c|}
\hline & \multicolumn{2}{|c|}{ GERD status } & \multirow[t]{2}{*}{ PR $(95 \% \mathrm{Cl})$} & \multirow[t]{2}{*}{$p$} \\
\hline & $\begin{array}{l}\text { Yes n } \\
\text { (\%) }\end{array}$ & No $\mathrm{n}(\%)$ & & \\
\hline \multicolumn{5}{|c|}{$\begin{array}{l}\text { E-cig smoking } \\
\text { status }\end{array}$} \\
\hline -Smoker & $13(52.0)$ & $\begin{array}{c}185 \\
(76.5)\end{array}$ & $\begin{array}{c}0.334(0.144- \\
0.772)\end{array}$ & 0.008 \\
\hline -Nonsmoker & $12(48.0)$ & $57(23.5)$ & 1 & \\
\hline
\end{tabular}

e-cig: electronic cigarette; GERD: gastroesophageal reflux disease.

Conclusions This population-based study showed that there is a statistically negative association between e-cig smoking and GERD in adult urban population. Further studies are needed to evaluate the association between e-cig smoking and GERD.

\section{IDDF2018-ABS-0116 A RARE CASE OF LOCALISED SMALL GASTRIC LANGERHANS CELL HISTIOCYTOSIS IN ADULT}

Kyoung Min Sohn*. Hansol Hospital, Korea, South

\subsection{6/gutjnl-2018-IDDFabstracts.113}

Background Langerhans cell histiocytosis (LCH) is characterised by a clonal proliferation of pathologic cells with the characteristics of Langerhans cells, in single or multiple organs.

Methods A 43 years old man was visited to our hospital for a routine health check-up. He had no symptoms, and his vital signs were normal. Physical examination revealed no abnormalities. He denied any past medical history and was not taking any medications. Laboratory examination findings also mostly were normal. Esophagogastroduodenoscopy showed a superficially elevated reddish polypoid lesion, less than $5 \mathrm{~mm}$ at the posterior wall, in the region of the fundus of the stomach, suggestive of fundic gland polyp, Yamada type I (figure 1a, b).

Results A cold biopsy was performed, and the histopathologic findings revealed many histiocytoid cells with indented nuclei and abundant eosinophilic infiltration in the deep mucosa (figure 1c, d). Immunohistochemically, the majority of the cells were strongly and diffusely positive for CD1a (figure 2a), S100 (figure 2b), CD68 (figure 2c) and negative for cytokeratin (figure $2 \mathrm{~d}$ ). We, therefore, made the diagnosis of $\mathrm{LCH}$ of the stomach. Following the establishment of the diagnosis of
LCH, a comprehensive workup was carried out to determine the extent of the disease, but there was no evidence of multisystem involvement. We performed ESD for complete removal of the lesion. But ESD specimen showed no remnant $\mathrm{LCH}$ lesion. The patient's 6 month follow-up visit revealed without local or systemic recurrence, and the patient remained in good health.

Conclusions This is a rare case of localised small gastric LCH detected by esophagogastroduodenoscopy, with the diagnosis confirmed by immunohistochemistry. The clinical characteristics of this disease remain unknown, and further detailed studies of a larger number of patients are needed.
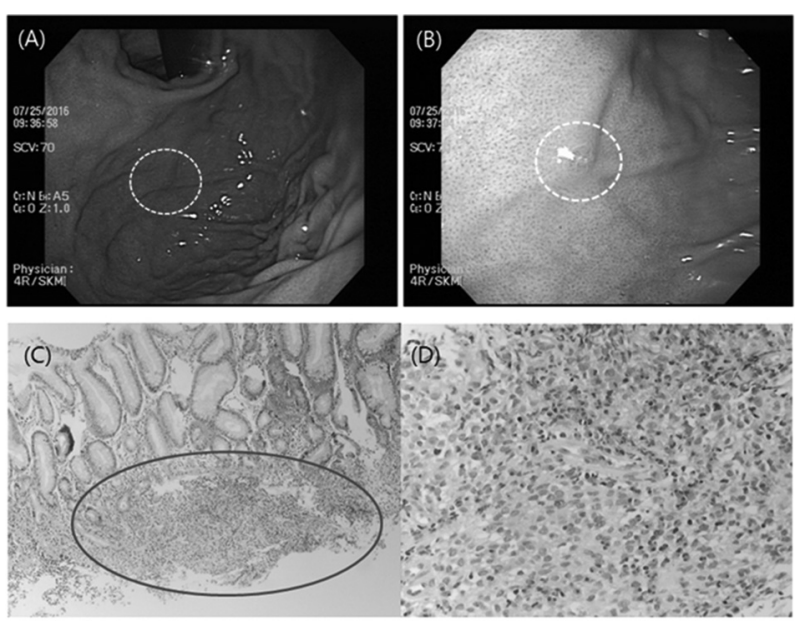

Abstract IDDF2018-ABS-0116 Figure 1 a, b, c, d

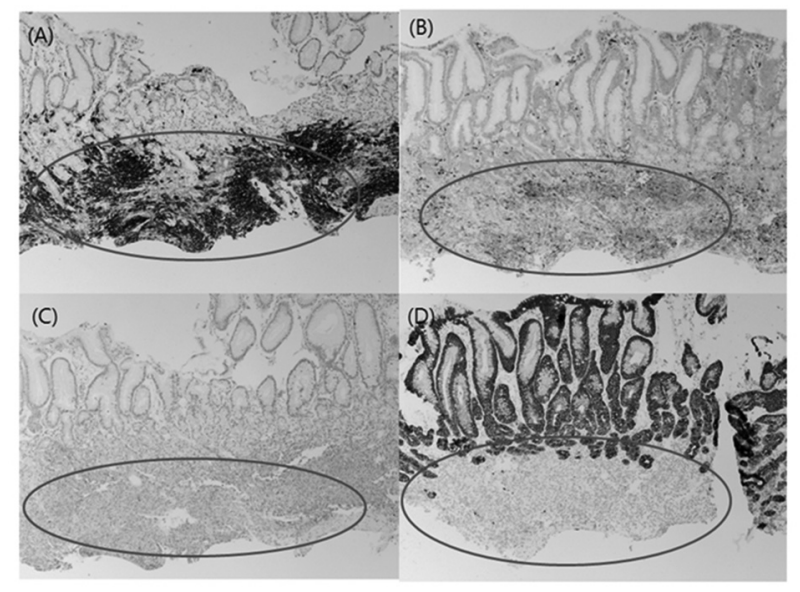

Abstract IDDF2018-ABS-0116 Figure 2 a, b, c, d

\section{IDDF2018-ABS-0118 CONGENITAL PANCREATIC BETA CELLS DISORDER - TWO CONTRASTING CASES}

Vikram Bhaskar*. Lady Hardinge Medical College, India

\subsection{6/gutjnl-2018-IDDFabstracts. 114}

Background Beta cells are unique cells in the pancreas that produce, store and release insulin. Here, we are reporting two contrasting cases, involving these beta cells, where at one end of the spectrum there is decrease insulin production, while on the other hand there is excessive insulin production. 
Methods Case 1: A 14 day old term male child, large for gestational age (birth weight- $4.5 \mathrm{~kg}$ ) presented with recurrent hypoglycaemia. On examination, the child was lethargic and hypoglycemic. The child was started on intravenous fluids. With the urine ketones being negative a critical sample was drawn at the time of hypoglycemia (RBS- $30 \mathrm{mg}$ ), which revealed insulin levels of $19.70 \mathrm{uIU} / \mathrm{ml}$, cortisol levels of $11.08 \mathrm{ug} / \mathrm{dl} \mathrm{hGH}$ levels of 12.90. With inappropriately high insulin and insulin (uIU/ml): glucose $(\mathrm{mg} / \mathrm{dl})$ ratio of 0.6 the child was diagnosed with persistent hyperinsulinemic hypoglycemia of infancy (PHIH). DOTA NOC PET CT scan showed mild diffuse DOTA NOC uptake in the pancreas more in the tail region of the pancreas ?nesidioblastosis. The child was started on diazoxide, and near total pancreatectomy was done later.

Case 2: A 5 month old female child was brought with complaints of multiple episodes of multi-focal tonic clonic seizures for the last 1 day. On routine investigations, patient had persistent hyperglycemia. Other investigations including CSF examination, liver and kidney function tests, skull ultrasound and serum electrolytes were within normal limit. Her C-peptide levels were inappropriately low $(<0.30 \mathrm{ng} / \mathrm{mL})$. Blood samples were sent to Royal Devon and Exeter NHS foundation trust, Exeter, UK, for genetic testing. She was found to be homozygous for a novel EIF2AK3 missense mutation, p.R1064Q (c.3191G>A), in exon 17. This mutation has never been reported before, but it affects a highly conserved nucleotide and in silico evidence suggest that it is likely to be pathogenic. This result is consistent with a diagnosis of Wolcott Rallison syndrome. Both the parents were found to be heterozygous.

Results Two absolutely contrasting cases of beta cell disorders are being described.

Conclusions Beta cells plays an important role in glucose metabolism in the body, and their defects may produce contrasting clinical conditions.

\section{IDDF2018-ABS-0119 COMPARISON OF FLUOROQUINOLONE INJECTION EFFECT FOR 3 DAYS CONTINUED WITH ORAL CONSUMPTION FOR 4 DAYS, WITH 7 DAYS INJECTION TO WOUND HEALING OF COMPLICATED APPENDICITIS SURGERY}

${ }^{1}$ Budhi Ida Bagus* ${ }^{2}$ Nirmala Antonius, ${ }^{3}$ Metria Ida Bagus, ${ }^{4}$ Mastini Ida Ayu Kade ${ }^{1}$ Surgery Department, Sebelas Maret University, Indonesia; ${ }^{2}$ Surgery Department, Moewardi General Hospital, Indonesia; ${ }^{3}$ Medical Faculty, Sebelas Maret University, Indonesia; ${ }^{4}$ Pharmacy Department, Moewardi General Hospital, Indonesia

\subsection{6/gutjnl-2018-IDDFabstracts.115}

Background Fluoroquinolone according to Sanford guide is a recommended antibiotic in cases of perforated appendicitis. Oral Levofloxacin has an almost complete bioavailability $(\geq 99 \%)$ absorbed by the body, proportional to the intravenous preparation. The aim of this study was to know the difference of injection fluoroquinolone for 3 days was continued orally 4 days with 7 days injection to wound healing operation of complicated appendicitis. There was lack of recommendation about this combination route antibiotics administration.

Methods This study was conducted in Surgery Department, Moewardi General Hospital, Indonesia from June - December 2016. Patients with complicated appendicitis who have performed laparotomy appendectomy, with a total of 16 samples.
Sampling was taken using consecutive sampling technique. After the operation was made two groups, the first group was given antibiotic levofloxacin $750 \mathrm{mg}$ by injection for 3 days, then given antibiotic levofloxacin tablets. The second group was given iv levofloxacin for 7 days. Wound medication was performed on the third, fifth, and seventh day, the clustering was done non-randomly. The data were tested with Fisher exact test.

Results Fisher exact test results obtained $p=1000 \quad(p>0,05)$ meaning that there is no significant difference between antibiotic fluoroquinolone injection for 3 days continued oral 4 days with injection 7 days on the wound healing. There was only 1 patient on combination route group has poor wound healing. All patients in the intravenous group had good wound healing after discharges from hospital.

Conclusions There was no significant difference in the use of fluoroquinolone antibiotic injection for 3 days followed by 4 day oral by 7 day injection of wound healing of complicated appendicitis. Combination route on fluoroquinolone antibiotics could reduce the length of stay with no significant complications.

\section{IDDF2018-ABS-0127 EARLY GASTRIC MUCINOUS ADENOCARCINOMAS AND SIGNET-RING CELL CARCINOMAS DID NOT SHOW HIGHER INVASION CAPACITY COMPARED WITH CONVENTIONAL ADENOCARCINOMA IN WESTERN POPULATION}

${ }^{1}$ Chenyue Tang ${ }^{*},{ }^{2}$ Qingwei Zhang. ${ }^{1}$ Ruijin Hospital, Shanghai Jiao Tong University School of Medicine, China; ${ }^{2}$ Renji Hospital, Shanghai Jiao Tong University School of Medicine, China

\subsection{6/gutjnl-2018-IDDFabstracts.116}

Background Little was known about the behaviour of early gastric mucinous adenocarcinomas (MAC) and signet-ring cell carcinomas (SRC) in Western populations. The purpose of this study was to investigate whether lymph node metastasis (LNM) and survival were correlated with histology including MAC, SRC and conventional adenocarcinomas (AC) in the Western populations.

Methods The Surveillance, Epidemiology, and End Results (SEER) database were used to identify all patients with surgically resected, histologically diagnosed early gastric cancer (EGC), including AC, MAC and SRC between 2004 and 2014. Logistic regression and competing risk model were used to explore whether LNM and survival differed among the above three subtypes of EGC.

Results Of 2632 patients eventually included in this study, MAC and SRC accounted for $1.13 \%$ and $17.31 \%$, respectively. Early gastric MAC or SRC patients had a numerically higher rate of LNM $(28.57 \%$ and $21.34 \%$ respectively) than $18.41 \%$ for AC patients without significant difference $(p=0.151)$. Patients with MAC and SRC demonstrated similar risk in LNM in relative to those with AC (odds ratio (OR), $1.16 ; 95 \%$ confidence interval $(\mathrm{CI}), 0.50-2.73, \mathrm{p}=0.728$ and OR, $1.22 ; 95 \% \mathrm{CI}, 0.92-1.63, \mathrm{p}=0.175$, respectively) in the multivariate logistic regression. The cause-specific survival of the patients with early gastric MAC or SRC was similar as that for AC patients $(p=0.0703)$ (figure 1). The cumulative incidence of cause-specific death was not significantly different between MAC, SRC and AC patients $(p=0.1094)$. MAC and SRC patients tended to have similar survival as compared 